\title{
PULMONARY FIBROSIS IN A WORKER USING AN ALUMINIUM POWDER
}

\author{
BY \\ J. WARREN JORDAN \\ From The Chest Clinic, Pontefract
}

(RECEIVED FOR PUBLICATION OCTOBER 13, 1960)

\begin{abstract}
A young woman was employed for five years as a "flash filler" in a fireworks factory, using a mixture containing aluminium powder. The powder reached a considerable concentration in the atmosphere of the small room in which the patient worked, after she had swept the room. This was done several times a day.

The patient had developed marked dyspnoea on mild exertion at the end of the five-year period. She was found to have limitation of chest movement with marked tracheal deviation. The radiograph showed the hila to be displaced upwards, a fine granular shadowing throughout the lung fields, and a small pulmonary cyst at the right lung apex. Lung function studies showed a marked reduction in lung volumes and a severely impaired diffusing capacity, while the mechanical function was only slightly below normal. Over the right upper lung lobe a small pneumothorax developed, which gradually resolved.

The similarity of this case to other reported cases in workers with particulate aluminium is noted, as is the view that rheumatoid disease may have had some action in the development of the lung lesion. An alternative diagnosis is considered. Finally, the possibility that personal idiosyncrasy may be responsible for the development of such lung lesions in aluminium workers is mentioned.
\end{abstract}

There is no general agreement about the effect of aluminium particles on the lungs of workers with this metal. Not only has it been held that powdered aluminium has no harmful effect on the lung, but claims have been made that it may be beneficial in reducing the incidence or severity of certain of the pneumoconioses (Crombie, Blaisdell, and MacPherson, 1944; Lancet, 1956). Because of these divergent views any unusual lesion found in the lungs of a worker in any process involving the inhalation of aluminium particles is of interest.

\section{Case Report}

The patient, a woman, was 26 years of age when first seen in 1955. At that time she had been unwell for two years, having developed abnormal shortness of breath which had gradually increased in severity. This symptom was accompanied by a slight cough, productive only of a little mucoid sputum. She complained of pain at the right lung base, pleuritic in character, and of tiredness, loss of appetite and of weight, sweating, and irregular menses. The past history contained nothing relevant to the present illness.

Occupational History.-On leaving school the patient undertook domestic service for six months, then for two years worked in a factory, bottling mineral waters. Subsequently for six months she returned to domestic service and then for a period of five years worked in a boot protector factory. Here she was engaged in various capacities. The nature and conditions of her work in this factory make it unlikely that they contributed materially to the development of the lung condition.

At the age of 21 she began work in a fireworks factory where for five years she was employed as a "flash filler". This involved working in a small room, relatively isolated for safety, and filling fireworks by hand, with a mixture of aluminium powder and potassium perchlorate. Much of the mixture was spilled and although the room was not usually dusty the powder reached a considerable concentration in the atmosphere whenever the room was swept. This operation was performed as a safety measure by the patient several times during the working day.

Findings.-The patient was a well-built and welldeveloped young woman with a little clubbing of the fingers and toes. The trachea was displaced to the right, and the chest movement was poor particularly of the right upper lobe, over which the breath sounds were harsh. A few moist sounds were heard over the left lung apex posteriorly. The postero-anterior radiograph of the chest (Fig. 1) showed both hila displaced upwards, 


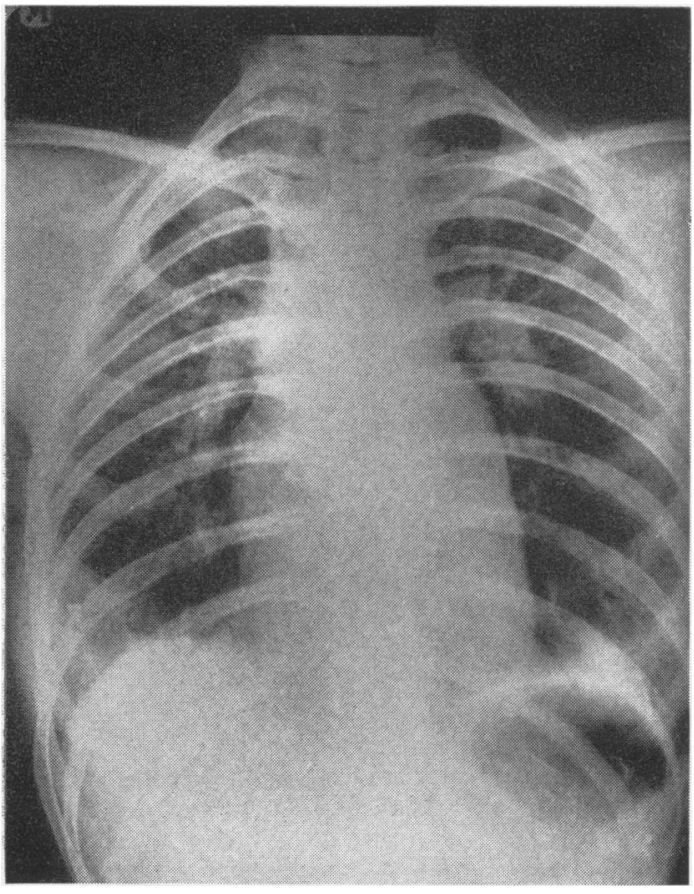

FIG. 1.-Postero-anterior radiograph.

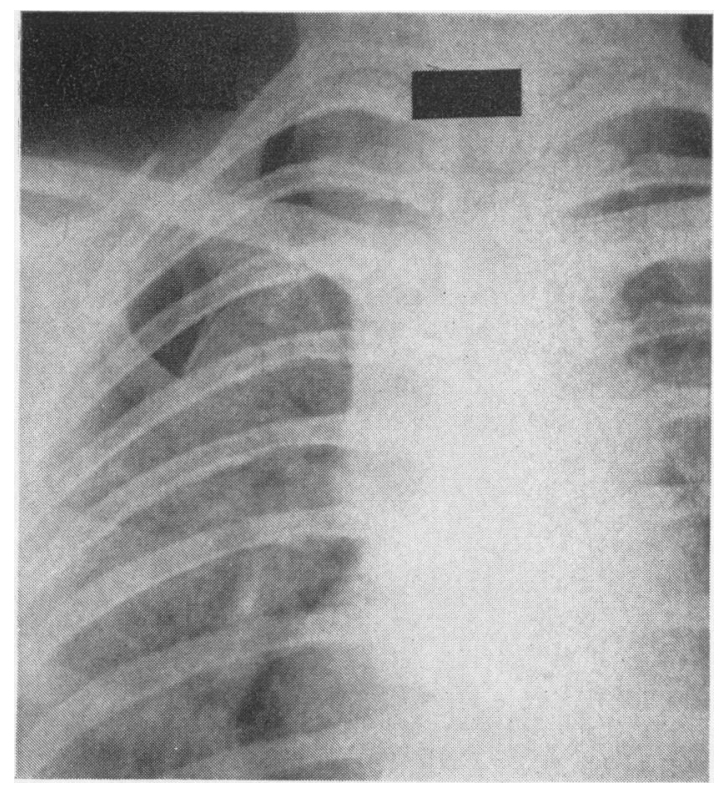

FIG. 2.-Spontaneous pneumothorax over right upper lobe. the trachea displaced to the right at the thoracic entry, and fine granular shadowing throughout the lung fields. There were diaphragmatic adhesions and calcified lesions at the right lung base. A pulmonary cyst was visible at the extreme right apex with a small right apical effusion. The white cell count and haemoglobin estimations were normal. The erythrocyte sedimentation rate was a little raised at $20 \mathrm{~mm}$. in the first hour (Westergren). The electrocardiograph showed right ventricular hypertrophy. The Wassermann and Kahn tests were negative. In view of the unusual radiological appearance, and the possibility that this might be due to acquired hypersensitivity to aluminium, skin testing with aluminium solutions was undertaken. The result of these tests was negative. Pulmonary function studies showed severe limitation of function due, in the main, to gross impairment of diffusing capacity but also to reduction of all the lung volumes. The values obtained were as follows: total lung capacity 2.971 .; vital capacity 1.851 .; maximum voluntary ventilation $56 \mathrm{l} . / \mathrm{min}$.; maximum expiratory flow rate $171 \mathrm{l} . / \mathrm{min}$. Diffusion capacity was $33 \%$ of the predicted normal.

Subsequent Course.-Five months after the patient was first seen, radiography revealed a small pneumothorax at the apex of the right lung (Fig. 2). Films taken at brief intervals showed the pneumothorax to be increasing in size. Because of this, and of the intensity of the fibrosis which the chest radiograph suggested, the prognosis at this time, even on a short-term basis, was not considered good. The patient was kept at rest in bed and the pneumothorax gradually resolved. At the time the pneumothorax was first observed, a guinea-pig, into which a specimen of the patient's sputum had been injected, developed a tuberculous lesion. This was the only occasion over a five-year period on which one of the many samples of the patient's sputum or bronchial secretion yielded a growth of tubercle bacilli. Because of this finding the patient was given a relatively brief course of anti-tuberculous drug treatment. Following these episodes, as a result of which the patient was kept at rest for a period, her general condition improved and she was able to return to work for a while, but subsequently, because of increasing dyspnoea, she has had to stop work. She remains fully ambulant and is able to carry out many household duties.

Four years after the initial examinations the patient complained of pain in the wrists, shoulders, and hands, and soon after developed fusiform swelling of the fingers. The latex screen test and the Rose Waaler reaction were positive (D.A.T. 64). Subsequently, the rheumatoid arthritis has become more marked.

\section{Discussion}

The diagnosis of the only case of pulmonary fibrosis in an aluminium worker so far reported in this country (Mitchell, 1959) was confirmed at autopsy, and in the present state of knowledge this is the only satisfactory proof of the diagnosis. Lung biopsy appears to be of doubtful value in the diagnosis of the condition, as the lung sample 
obtained may be quite unrepresentative of the lung as a whole. In the present case the procedure was considered but rejected in view of the spontaneous pneumothorax and the possible danger to the patient were such a condition to recur.

Of alternative diagnoses to that of pulmonary fibrosis produced by aluminium particles or aluminium lung disease, pulmonary tuberculosis appears the most probable. There are, however, serious objections to accepting such a diagnosis. The clinical course of the disease and the radiological appearance of the chest are quite atypical of pulmonary tuberculosis in a young woman, there being an absence of significant sputum or haemoptysis at any stage, and an absence of cavitation at the time the patient was first seen despite the presence of an untreated disease process widespread throughout the lungs. Dyspnoea has been the predominant symptom and gross pulmonary fibrosis appears to be the main form of the lesion. In favour of the view that the fibrosis is the result of inhalation of aluminium particles is the similarity of the findings in the case here reported with those reported by Shaver (1948), Goralewski (1947) and Mitchell (1959). In particular, the radiological appearance of this case is very similar in the gross fibrosis, the widening of the upper mediastinal shadow, the granular shadowing, the diaphragmatic adhesions, the presence of bulbous emphysema, and finally the development of a spontaneous pneumothorax, to many of the cases reported by Shaver (personal communication). The particle size of the aluminium powder with which the patient worked varied, but many particles were less than $5 \mu$, i.e. sufficiently small to be inhaled into the smallest divisions of the bronchial tree.

It is possible that the patient's rheumatoid condition has had some role in the development of the lung lesion. Cases have been described of patients with rheumatoid disease who developed lung lesions for which no other cause was found (Ellman and Ball, 1948; Price and Skelton, 1956). The radiological appearance of these lesions is, however, completely dissimilar from that seen in the case recorded above. Caplan (1953) first described the radiological opacity which may appear when coalworkers' pneumoconiosis occurs with rheumatoid arthritis. Further cases have been reported of pneumoconiosis modified by rheumatoid disease in occupations other than that of coalworking
(Caplan, Cowen, and Gough, 1958; Campbell, 1958; Rickards and Barretı, 1958). It appears possible that the patient's rheumatoid disease may have been a factor in the development or modification of the lung lesions. Such a role could only be demonstrated by histological examination of the lesions (Gough, Rivers, and Seal, 1955; Caplan et al., 1958).

No similar cases have been discovered among the workers at the factory where the patient was employed. This may be explained by the fact that few, if any, of the other workers were employed on this process for a similar length of time; the process was not popular with the employees and one worker could produce a high proportion of the output required; moreover, the turnover of workers at the factory, mainly young women, was fairly high. The use of this mixture in fireworks ceased five years ago.

There remains the problem of whether there may be some personal idiosyncrasy in the production of lung lesions in workers with fine aluminium powder. Goralewski (1947) suggests that the degree of exposure to the powder is the factor of importance in the development of "aluminium lung". Shaver (1948) noted that some workers were exposed for lengthy periods to the fumes of aluminium oxide furnaces without developing any abnormal change in the chest radiograph, while others developed gross changes in a fraction of such time. He mentioned two instances in which both father and son developed the disease.

My thanks are due to Dr. C. S. Darke, Dr. John Mitchell and Professor R. E. Lane for help and encouragement; to Dr. C. G. Shaver who has given me the benefit of his experience; to Dr. J. C. Gilson and his colleagues who examined the powder for particle size, to Dr. Mary Catterall who carried out the lung function studies, and to Drs. W. D. Buchanan, J. Tombleson and A. H. Baynes of H.M. Factory Inspectorate for help with a number of problems.

\section{REFERENCES}

Campbell, J. A. (1958). Thorax, 13, 177

Caplan, A. (1953). Ibid., 8, 29.

Cr, Cowen, E. D. H., and Gough, J. (1958), Ibid. 13, 181.

Crombie, D. W., Blaisdell, J. L., and MacPherson, G. (1944). Canad. med. Ass. J., $50,318$.

Ellman, P., and Ball, R. E. (1948). Brit. med. J., 2, 816

Goralewski, G. (1947). Z. ges. inn Med., 2,665 .

Gough, J., Rivers, D., and Seal, R. M. E. (1955). Thorax, 10, 9.

Lancet (1956). 2, 500 .

Mitchell, J. (1959). Brit. J. industr. Med., 16, 123.

Price, T. M. L., and Skelton, M. O. (1956). Thorax, 11, 234.

Rickards, A. G., and Barrett, G. M. (1958). Ibid., 13, 185.

Shaver, C. G. (1948). Occup. Med., 5, 718. 